\title{
DESDOBRAMENTOS, RESSONÂNCIAS, CONTÁGIOS... AS PRODUÇÕES DAS CRIANÇAS SOBRE O PAPEL E SEUS CORTES-FLUXOS DESEJANTES E FABULADORES
}

\author{
DEVELOPMENTS, RESONANCES, CONTACTS... CHILDREN'S PRODUCTIONS ON \\ PAPER AND ITS DESIRING AND FABULATING CUT-FLOWS
}

\author{
Camilla Borini Vazzoler ${ }^{1}$
}

\begin{abstract}
Resumo: O que enuncia uma criança quando desenha? É de comum acordo que os desenhos das crianças fazem parte da rotina dos centros de educação infantil, e, pensando na potência desses registros, buscou-se problematizar a força dos desenhos das crianças por meio de uma aulaacontecimento com um personagem do folclore brasileiro. Desse modo, visou-se movimentar o pensamento em movimento com as fabulações criadas pelas crianças nos seus processos de criação desejante e imanente. Ao usarem lápis colorido e papel, produzem e criam mundos, fabulam outros modos de pensar, criam cortes-fluxos, pois algo passou pelo seu corpo, e, ao criarem, a virtualidade atualizou-se em traços intensivos impressos em um papel. A potência deste texto está nos desenhos das crianças e na maneira como as professoras se afetam com as forças que elas produzem, ao pintarem o mundo, criando desdobramentos, ressonâncias e contágios...
\end{abstract}

Palavras-chave: Criança; fabulação; desenhos.

\begin{abstract}
What does a child say when he draws? It is common agreement that children's drawings are part of the routine of early childhood education centers, and thinking about the power of these records we seek to problematize the strength of children's drawings based on an event-class with a character from Brazilian folklore. In this way, we aim to put thinking in motion, with the fabulations created by children in their desiring and immanent creation processes. When using colored pencils and paper they produce and create worlds, they fabulous other ways of thinking, they create cut-flows, because something has passed through your body, and when creating, virtuality has been updated in intensive lines printed on paper. The power of this text is in the children's drawings and how we are affected by the forces they produce when painting the world, creating developments, resonances and contagions...
\end{abstract}

Keywords: Child; fabulation; drawings.

\footnotetext{
${ }^{1}$ Doutoranda do Programa de Pós Graduação em Educação da Universidade Federal do Espírito Santo. E-mail: camillavazzoler@gmail.com.
} 


\section{Desdobramentos...}

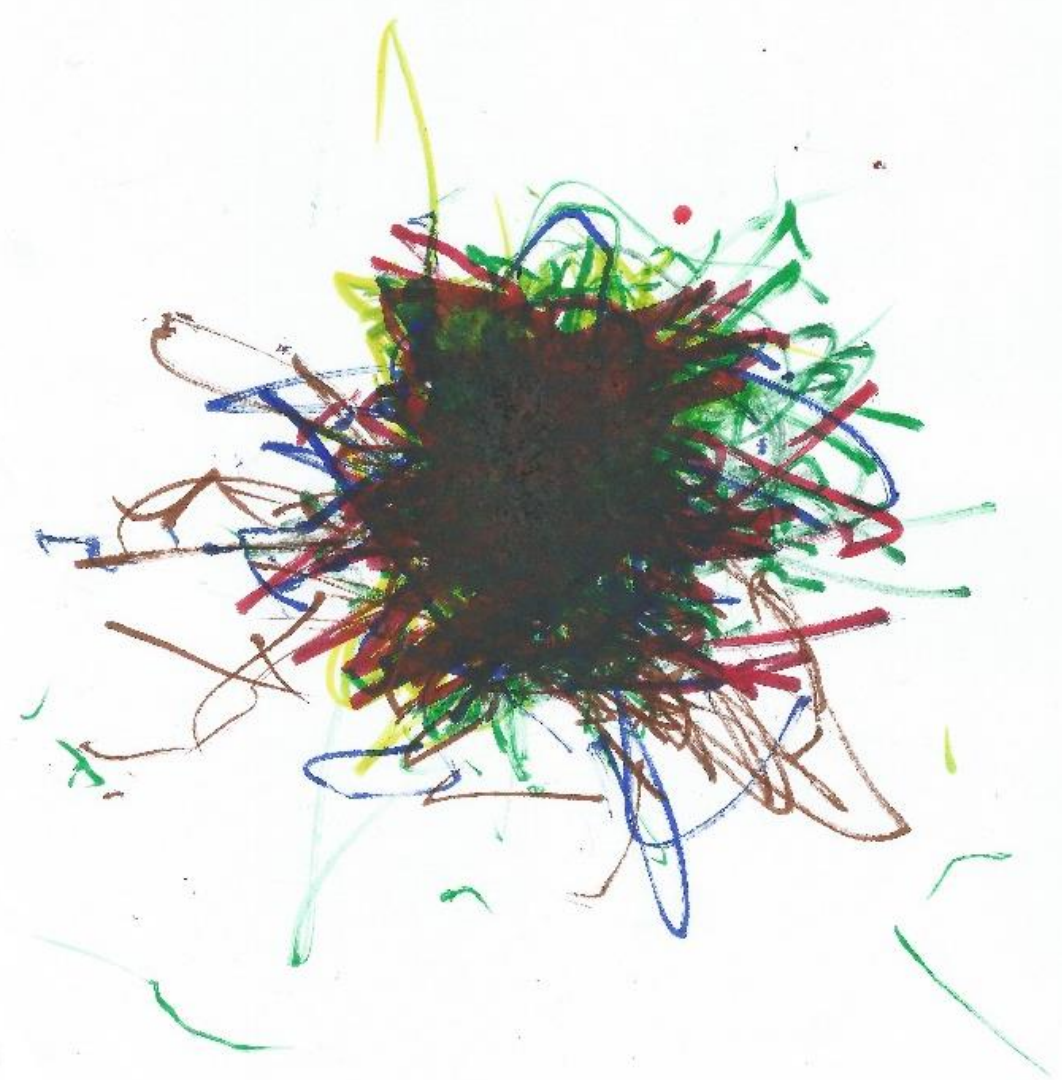

Figura 1 - Cortes-fluxos fabuladores - Fonte: Arquivo pessoal

Dificilmente encontramos um centro de educação infantil que não se utilize do desenho como possibilidade de registro das atividades pedagógicas produzidas por crianças e professoras. Os riscos, traços, rabiscos e desenhos são produzidos quase que como uma atividade rotineira, seja para representar uma história, uma atividade de algum momento, seja para desenhar em um momento livre. É comum, por exemplo, encontrá-los pendurados pelas paredes. Podem ser produzidos com uma finalidade pedagógica específica ou simplesmente como um "passatempo" durante a rotina diária; também são muito utilizados como ferramenta avaliativa, compondo os portfólios e fazendo parte os relatórios. É inegável, portanto, como os desenhos das crianças compõem as práticas cotidianas nos centros de educação infantil.

Sim, as crianças desenham, rabiscam, criam traços, imaginam, fabulam...

Podem até parecer que aqueles traços ou rabiscos digam pouca coisa, ainda que seja um emaranhado de cores que nada dizem. No encontro com esses desenhos, podemos debruçar-nos em uma descrição literal do pensamento das crianças, buscando para isso que elas traduzam o que representaram nas folhas de papel. Há também a possibilidade de forçar as crianças a desenhar o que indicamos ou vislumbramos. Pode ser que, ao visualizarmos um desenho, sejamos atravessados pelo desejo de classificação entre o "bonito" ou o "feio".

Sim, há um desejo por entender os desenhos das crianças.

A questão que se apresenta, desse modo, é como temos pensado os registros das crianças nos centros de educação. Em quais os momentos os utilizamos? Por que os utilizamos? Qual a 
força do desenho em nossas práticas pedagógicas? Como as crianças se expressam por meio dos registros pictográficos? Estamos atentos e sensíveis às suas enunciações artísticas? É possível pensar o desenho como um signo aprendente?

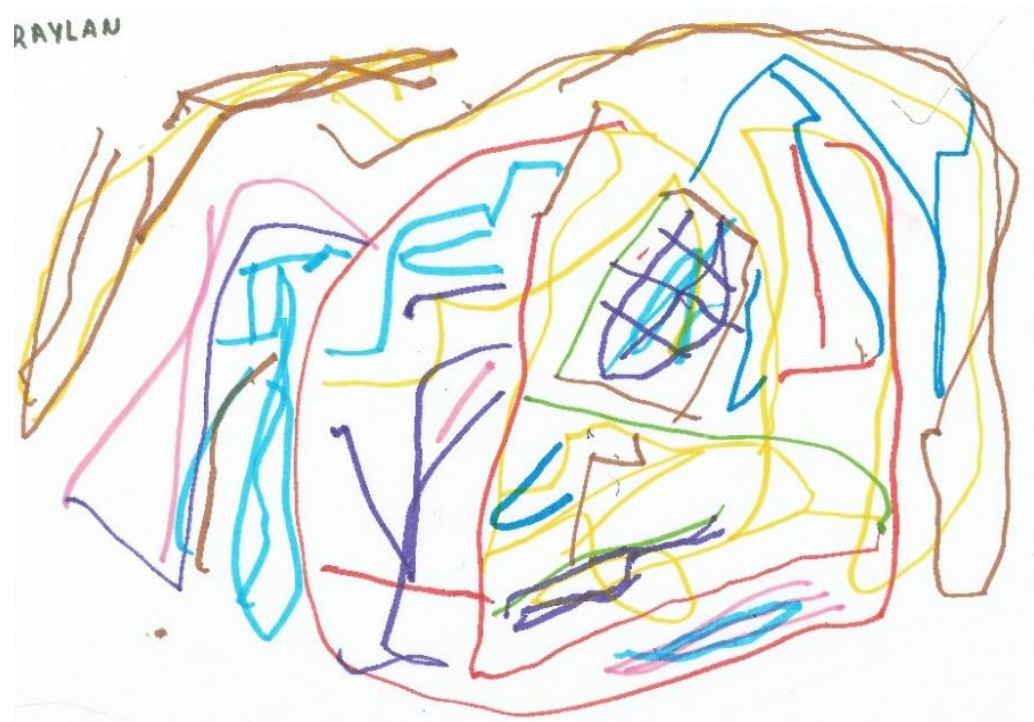

Figura 2 - Desdobramentos... - Fonte: Arquivo pessoal

Com base nessas indagações, é importante afirmarmos que, em relação às produções das crianças, não buscamos descrições, classificações, nomenclaturas, traduções ou qualquer dispositivo que anseie por captar o pensamento das crianças que, neste caso, se impressa por meio do desenho. Não nos interessa "pedagogizar" ou "psicologizar" os desenhos; não temos a pretensão de elucidar os porquês elas desenham ou como desenham; não nos compete catalogar as formas desenhadas; não queremos determinar uma terminologia para os registros; ou ainda perguntar por que traduzam seus desenhos, para que escrevamos do lado o que aquela intensidade representa. Nada disso nos interessa.

A aposta que fazemos aqui é pensar que os traços artísticos expressam uma força, um fluxo, uma intensidade, uma linha de fuga, os quais podem indicar caminhos aprendentes, máquinas desejantes que forçam o pensamento na erupção de outros modos de produção que são "[...] cortes-fluxos de onde o desejo irrompem, que são a sua produtividade e que sempre implantam o produzir do produto" (DELEUZE; GUATTARI, 2010, p. 55).

Sem dúvida, os desenhos expressam uma força. E quem pode engaiolar um fluxo intensivo em uma descrição? Nesse sentido, objetivamos movimentar o pensamento com as fabulações criadas pelas crianças nos seus processos de criação desejante e imanente. Ao usarem lápis colorido e papel, produzem e criam mundos, fabulam outros modos de pensar, criam cortes-fluxos, pois algo passou pelo seu corpo, e, ao criarem, a virtualidade atualizou-se em traços intensivos impressos em um papel.

No encontro das crianças com os acontecimentos, os signos artísticos, os lápis e os papeis, há desdobramentos que derivam ao infinito. 


\section{Ressonâncias...}

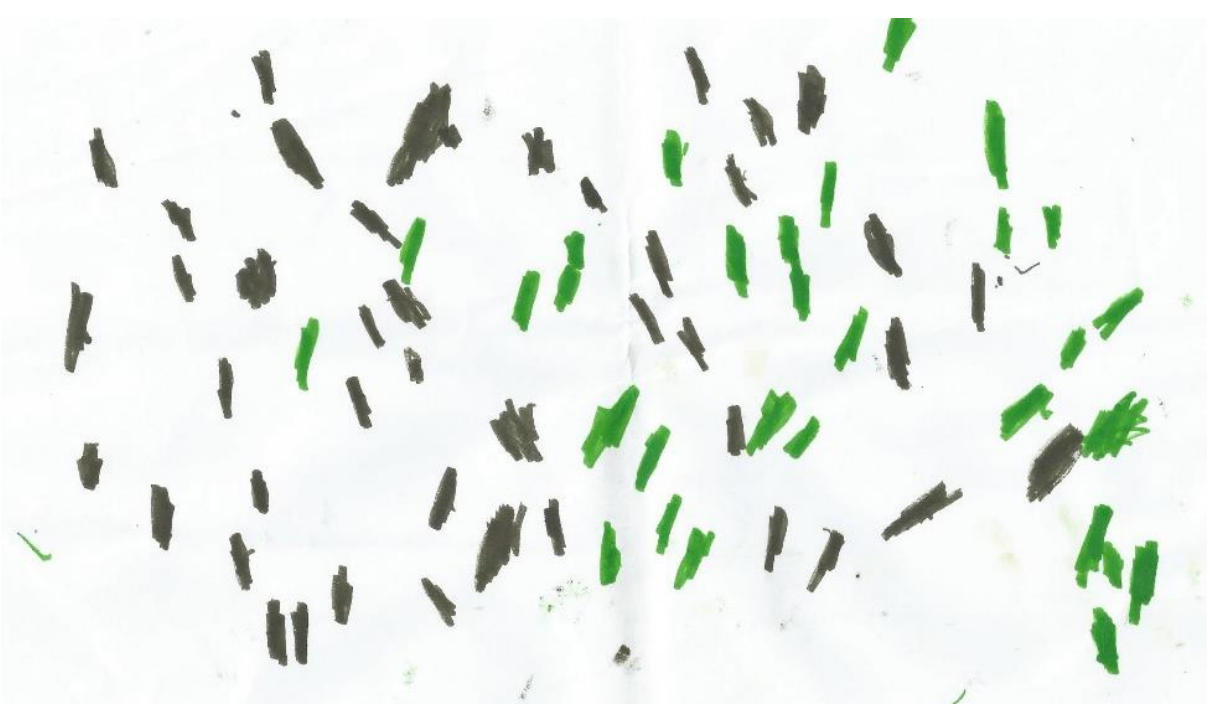

Figura 3 - Afecções, o que pode um corpo? - Fonte: Arquivo pessoal

O que pode uma criança? Quais fluxos e linhas desejantes atravessam o caos em uma sala de aula? Devindo, as crianças produzem processos imanentes de composição, cortes-fluxos desejantes que ressoam em processos criativos, fabulativos, criam mundos e aprendências, as quais não podem ser catalogadas ou registradas de modo redundante ou universal, pois cada criança produzirá ressonâncias variadas sobre os acontecimentos que experiencia. Nesse sentido, podemos perguntar, com Spinoza (2007), o que pode um corpo.

Deleuze (2017) afirma, a partir de Spinoza, que o poder de um corpo é a natureza e os seus limites, no que concerne ao seu poder de ser afetado. Para tanto, devemos considerar que a potência de um corpo corresponde a dois aspectos que definem a sua existência: o movimento e o repouso, em composição com a sua constante relação entre os corpos, possuindo, assim duas, faces inseparáveis: o afetar e o ser afetado.

Desse modo, entendemos, apoiados Spinoza (2007), que a potência de um corpo é um princípio tanto de ação quanto de afecções. "Dessa conjunção segue, por exemplo, que uma das características que definem os corpos mais complexos e potentes é, justamente, a aptidão para ser afetado de diversas formas ao mesmo tempo" (MERÇON, 2009. p. 41). 


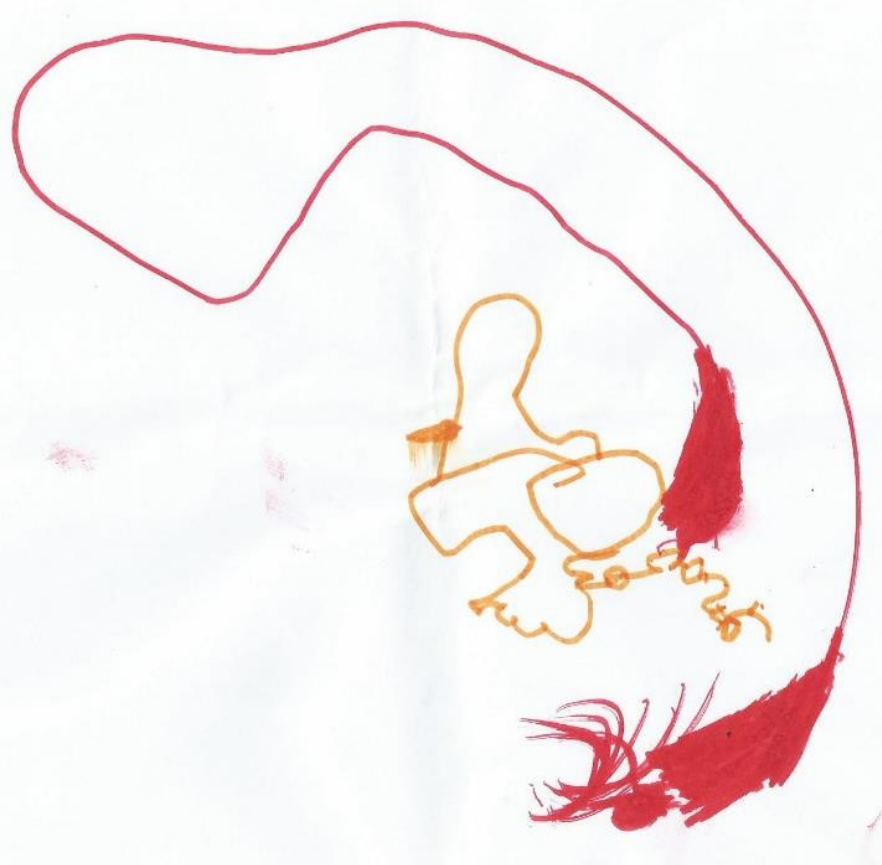

Figura 4 - Intensidades... - Fonte: Arquivo pessoal

Reconhecemos, assim, a potência que há na capacidade de os indivíduos se colocarem em relação, a fim de que produzam conhecimentos, desejos, afetos e afectos. Corpos vibráteis em composição com as intensidades de outros corpos, agenciando formas e forças coletivas. Quando falamos em corpo, fazemos menção ao corpo intensivo que, nas interações com outros corpos, ativa produções de experiências estéticas, cria modos de existência, processos de subjetivação. Forças que operam no campo das sensações. Intensidades que movimentam pensamentos.

Entendemos que o pensamento nasce no corpo, quando esse deixa afetar-se por um signo. Para tanto, o corpo físico também tem fundamental importância, uma vez que ele precisa estar vivo para agenciar sentidos. Essa é a grande beleza que envolve os processos de construção da coletividade, pois, ainda que os corpos físicos permaneçam "inertes", podem ser atravessados pelos afetos.

Assim, dizemos que o corpo não é restritamente um sujeito, mas também uma força com outros sentidos de vida e de existência, que, no encontro com outras forças, produzem potência. Embora um corpo se mostre aparentemente despotencializado, endurecido em suas ações e pensamentos, insensível ante as miudezas da vida, ele pode, no encontro com um signo (uma coisa, uma música, uma poesia, um cheiro, um corpo, uma cor...), ser afetado por outra forma de existência, e, então, esse pensamento se move. Há aí o rompimento da ideia do pensamento racional, preconcebido pela ciência moderna hegemônica que, por vezes, delimita o corpo à sua dimensão orgânica. Esse corpo vivencial se entrega às paixões afectivas e busca agora construir outros sentidos de vida. Agencia máquinas desejantes. 


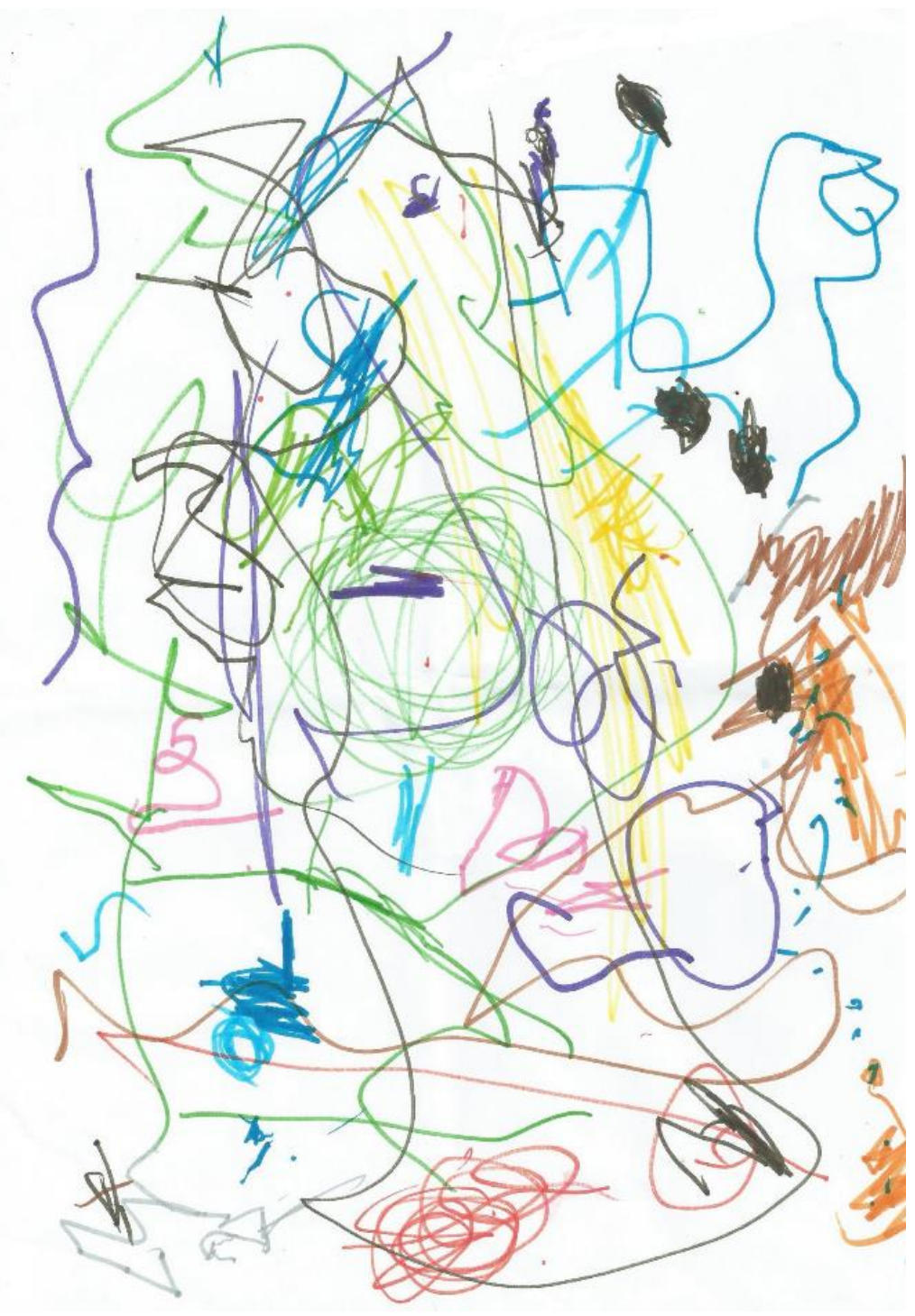

Figura 5 - Cortes-fluxos... - Fonte: Arquivo pessoal

As ressonâncias produzidas pelas afecções dos corpos produzirão processos aprendentes singulares mediante os processos de subjetivação, nos quais a fabulação/criação produzirá cortes-fluxos desejantes no caos. Por esse motivo, não apostamos na ideia de representação ou descrição do que as crianças desenham, para nós, pensamos que a produção de um desenho diz muito mais que traços, cores e formas; elas exprimem um certo modo de pensar, são virtualidades que se atualizam na produção de modos diferenciais de se colocar no mundo e movimentar o pensamento, na produção de máquinas desejantes. Diante disso, lançamos a seguinte questão: $\mathrm{O}$ que enuncia uma criança quando registra uma intensidade em fluxo?

Com Deleuze (2007) pensamos em pintar com as forças do mundo, o registro não se limita a reproduzir ou a inventar formas, e sim captar/exprimir a força, ou seja, quando desenhamos, há uma tentativa de tornar visíveis forças que não são visíveis. "A força está em relação estreita com a sensação: é preciso que uma força se exerça sobre um corpo, na forma de uma onda, para que haja sensação" (DELEUZE, 2007, p. 62).

$\mathrm{Na}$ atualização da sua força-pensamento, as crianças criam linhas de fuga, fabulações, cujas intensidades que circulam em meio as expressividades vão traçando outros possíveis e fazem cortes nos fluxos de produção. 


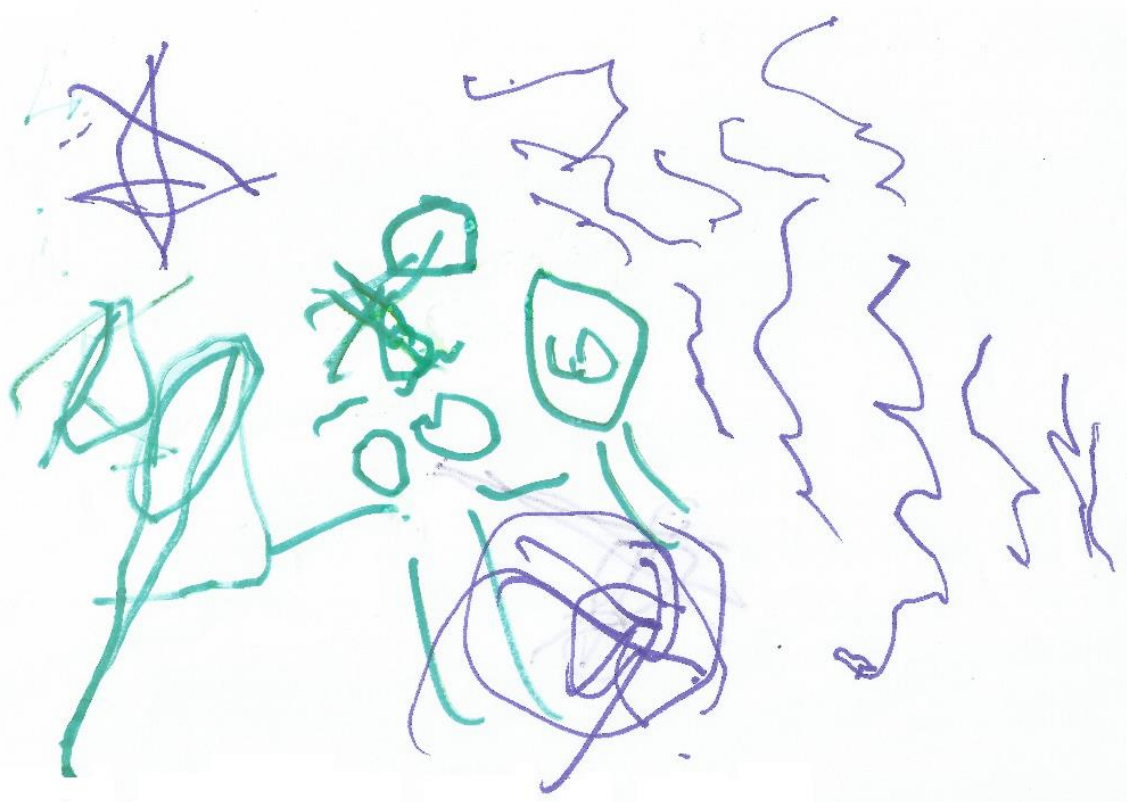

Figura 6 - Ressonâncias... - Fonte: Arquivo pessoal

Assim, na composição entre as crianças e com os adultos, o plano virtual atualiza-se traçando mapas intensivos por meio de vetores ainda não pensados e vividos. São ressonâncias que se atualizaram mediante as falas, registros e relações singulares das crianças com personagens virtuais.

\section{Contágios...}

Quando afetados por signos intensivos, as crianças pintam com as forças do mundo, produzem cortes-fluxos desejantes no caos e enunciam as intensidades que atravessam os seus corpos. Como descrever essa intensidade? Como registrar um afeto? Como desenhar um cheiro, um som, uma fabulação?

Os desenhos que compõem este texto referem-se a registros pictográficos produzidos pelas crianças após uma aula em que tiveram um encontro inesperado com um personagem folclórico e uma poção mágica ${ }^{2}$. As intensidades que passaram pelos seus corpos criaram um desejo imanente pela composição, investigação e fabulação. Elas foram contagiadas pelas intensidades de um acontecimento e desejaram pintar com as forças do mundo.

Um encontro entre corpos, cortes-fluxos desejantes que produziram desdobramentos e ressonância e contágios...

2 O planejamento para aquela turma consistia em experienciar e conhecer o folclore brasileiro por meio das histórias do Sítio do Pica Pau Amarelo, de Monteiro Lobato. Nesta aula, a Cuca presenteou a turma com uma de suas poções mágicas, a qual quimicamente consiste em construir uma escala de $\mathrm{pH}$ utilizando extrato de repolhoroxo e outros materiais de fácil acesso, como álcool, vinagre de álcool e detergente líquido transparente. Quando o estrato de repolho-roxo entra em contato com os líquidos incolores, ele muda de cor, o que torna essa poção mágica para as crianças e nos oferece possibilidades de criação, investigação e fabulação. 


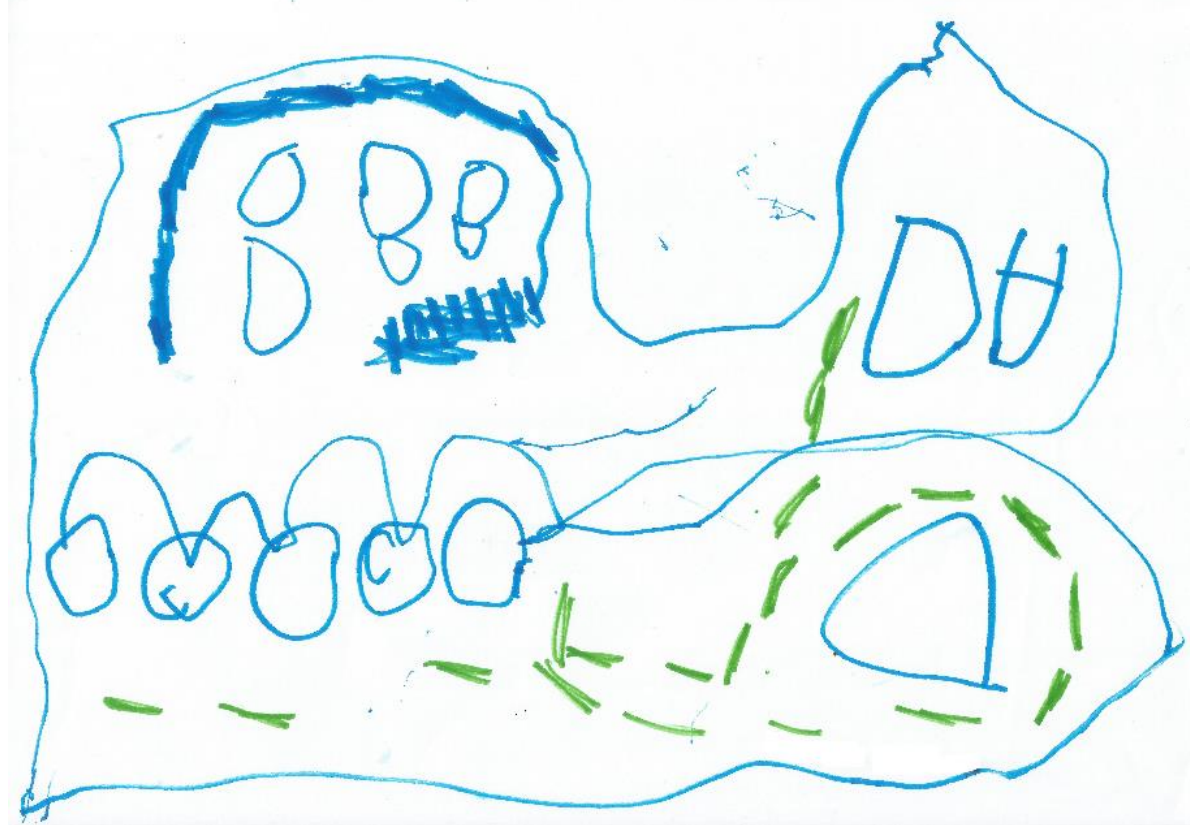

Figura 7 - Conexões, contágios, intensidades... - Fonte: Arquivo pessoal

Em uma tarde, aparentemente comum em um centro de educação infantil, adentramos a sala com o grupo de crianças de 3 anos e encontramos uma mesa com vários copos cheios de líquidos transparentes, parecendo água, e um imenso caldeirão. Atentas àqueles objetos, as crianças questionavam-se e suspeitavam que uma certa feiticeira com cara de jacaré poderia ter visitado o Centro de Educação Infantil. Resolvemos arriscar-nos e experimentamos misturar os líquidos para ver o que aconteceria. A cada nova mistura, uma cor diferente! Como um líquido transparente poderia se tornar roxo? Rosa? Verde?

Com olhares curiosos, as crianças analisavam cada etapa do experimente. Investigavam cada movimento da professora. Trocavam opiniões sobre as possíveis soluções daquele mistério. Analisavam os cheiros e as cores dos líquidos. Articulavam o pensamento no desejo de desvendar aquele fato extraordinário.

Uma criança destemida resolveu tocar o líquido mágico com um dedo. Até que, de súbito, o feitiço fez efeito! A criança transformou-se em um lobo! Espantadas e simultaneamente maravilhadas, as outras crianças tentavam entender aquele novo movimento, perguntavam o que estava acontecendo. Mas não tinha jeito, o lobo só uivava! Parecia que o feitiço ainda não estava completo! Algumas galinhas começaram a cacarejar. Um dragão apareceu! E agora o que fazer? Como podemos resolver esse feitiço? Uma das crianças solicita que as demais voltem ao normal. 


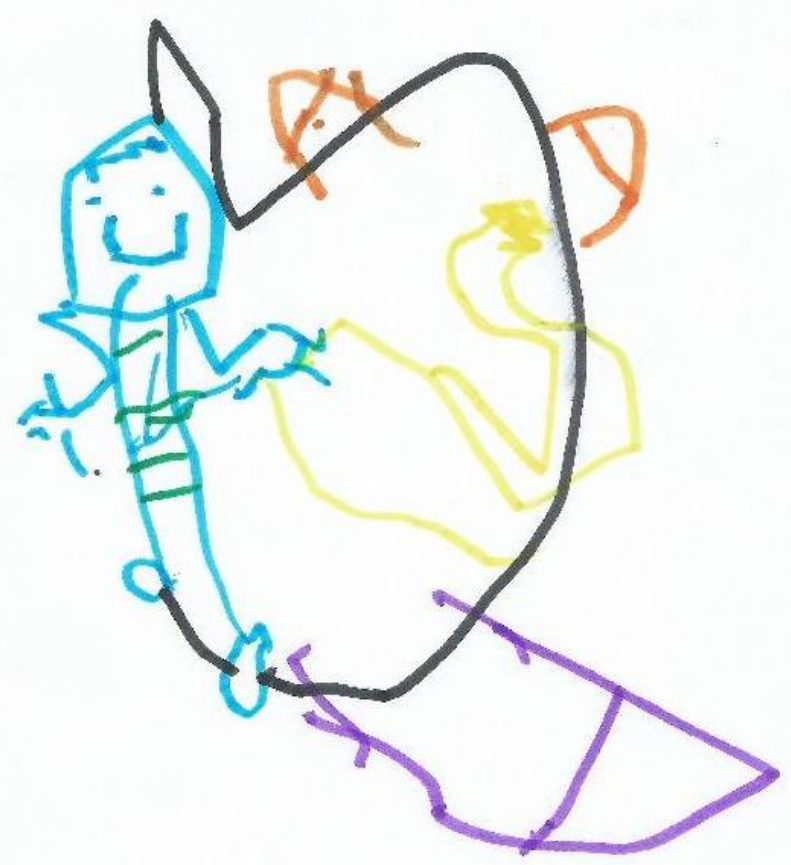

Figura 8 - O virtual... - Fonte: Arquivo pessoal

As fabulações criadas naquele turbilhão de agenciamentos davam passagem a afetos e afecções que afirmam a vontade imanente das crianças por processos de criação, investigação e fabulação. As hipóteses criadas derivavam ao infinito. Havia crianças que ansiavam por maior contágio aquelas intensidades, já outras buscavam a manutenção do espaçotempo. Assim, os corpos anunciavam os processos de corte-fluxo e a maneira como as intensidades virtuais os afetavam. A fabulação, assim, percorre caminhos inimagináveis, e o virtual se atualizará no encontro entre os corpos intensivos, por isso "[...] cada virtual tem uma maneira que lhe é própria de aceitar ou de negar aquilo que o exprime inadequadamente; ele se torna mais preciso tanto nas afirmações quanto pelas negações sucessivas que o cercam e fazem dele um ser problemático" (LAPOUJADE, 2017, p. 40).

Sendo assim, nos encontros com os agenciamentos, cada corpo intensivo vibrará de uma infinidade de maneiras e, com isso, produzirá cortes-fluxos nas máquinas desejantes. O que conta são as intensidades e os processos de produção imanente do pensamento. O que nos interessa nos processos curriculares com as crianças são as forças que elas agenciam, cujas linhas cortam o caos produzindo desdobramentos, ressonâncias e contágios. A potência está justamente em entender esses fluxos, e, ao experienciá-los com as crianças, produzir processos de aprendizagens diferenciais que busquem na diferença possibilidades de criação e fabulação curricular. 


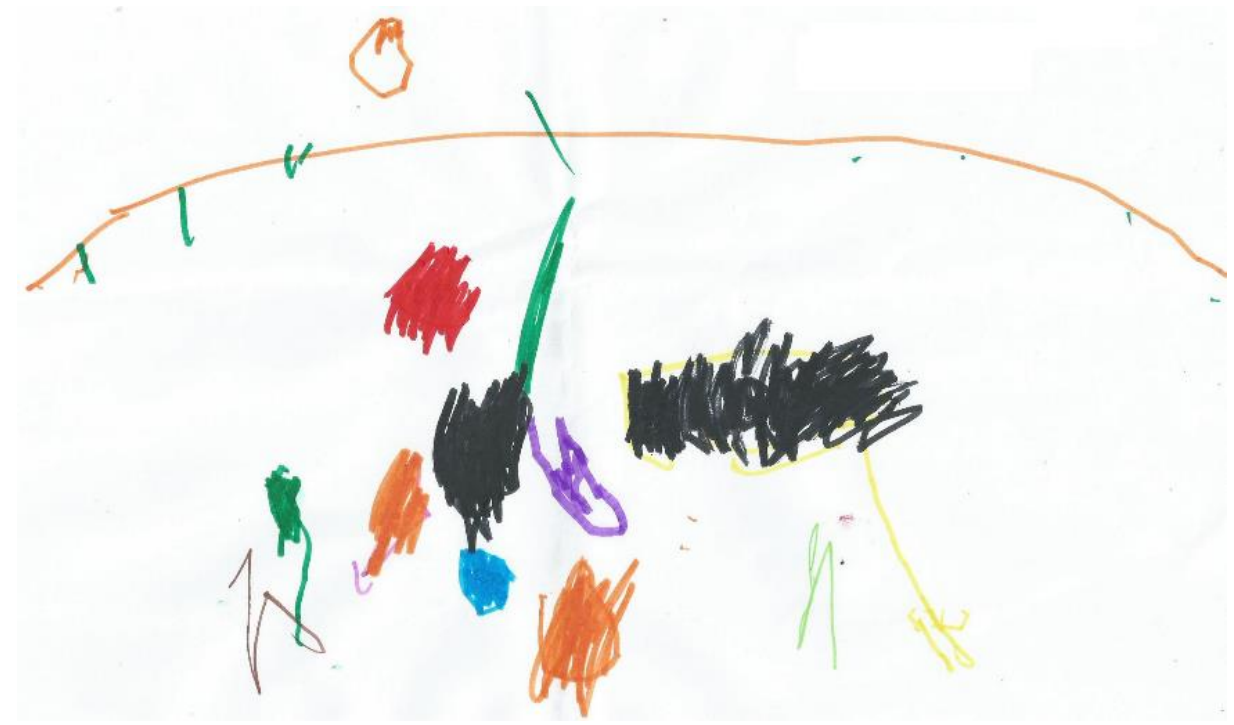

Figura 9 - Afecções... - Fonte: Arquivo pessoal

Com as crianças, portanto, fabulamos soluções para decifrar o destemido feitiço. Até que uma criança fez uma sugestão: E se misturássemos todos os feitiços? Sugeriu outra: Poderia dar certo? Envolvemo-nos com as crianças nessa solução. Enquanto um grupo desejava resolver o problema criando pelo feitiço da feiticeira com cara de jacaré, outras ansiavam em permanecer transformadas em dragão, galinhas e cachorro. Dentro do caldeirão, jogamos todos os líquidos coloridos e o forte cheiro daquele superfeitiço trouxe as crianças de volta.

As crianças vibravam diante da inusitada solução.

A partir do feitiço da Cuca, muitos foram os desdobramentos. A curiosidade e a investigação da mudança de cor de cada copo tomavam conta daquele espaçotempo. A vibração dos corpos ansiava por desvendar aquele mistério fabuloso. Muitos foram os argumentos, algumas queriam procurar a destemida feiticeira, outras queriam tomar o superfeitiço, havia aquelas que pareciam não entender o que havia acontecido naquela manhã, buscando a manutenção e a negação daquela aula-acontecimento. Mas uma coisa nós professoras sabíamos: aquela aula provocou nos corpos possibilidades que não era possível descrever. Diante do deslocamento, decidimos pedir que registrassem o que aconteceu perguntando: $\mathrm{O}$ que a Cuca poderia fazer com o feitiço? ${ }^{3}$

\footnotetext{
${ }^{3}$ É importante considerar que o planejamento daquela aula não consistia em culminar em desenhos produzidos pelas crianças. Tal ferramenta de registro foi utilizada pela intensidade que foi experenciada naquela aula-acontecimento.
} 
Mas como pintar uma sensação? Como representar um uivo? Um cheiro? Um som? Uma sensação que passou pelo seu corpo? Desafiamos as crianças a expressar aquela experiência singular em um papel, pois elas continuavam em produção desejante. Quando o desejo cresce e transborda, ele cria, e as crianças continuam em fabulação, em invenção. Investigando o acontecimento singular, elas pensavam e pintavam as forças daquele feitiço, imprimiam no papel os desejos daquela intensidade vivida em seus corpos, em seus fluxos e cortes.

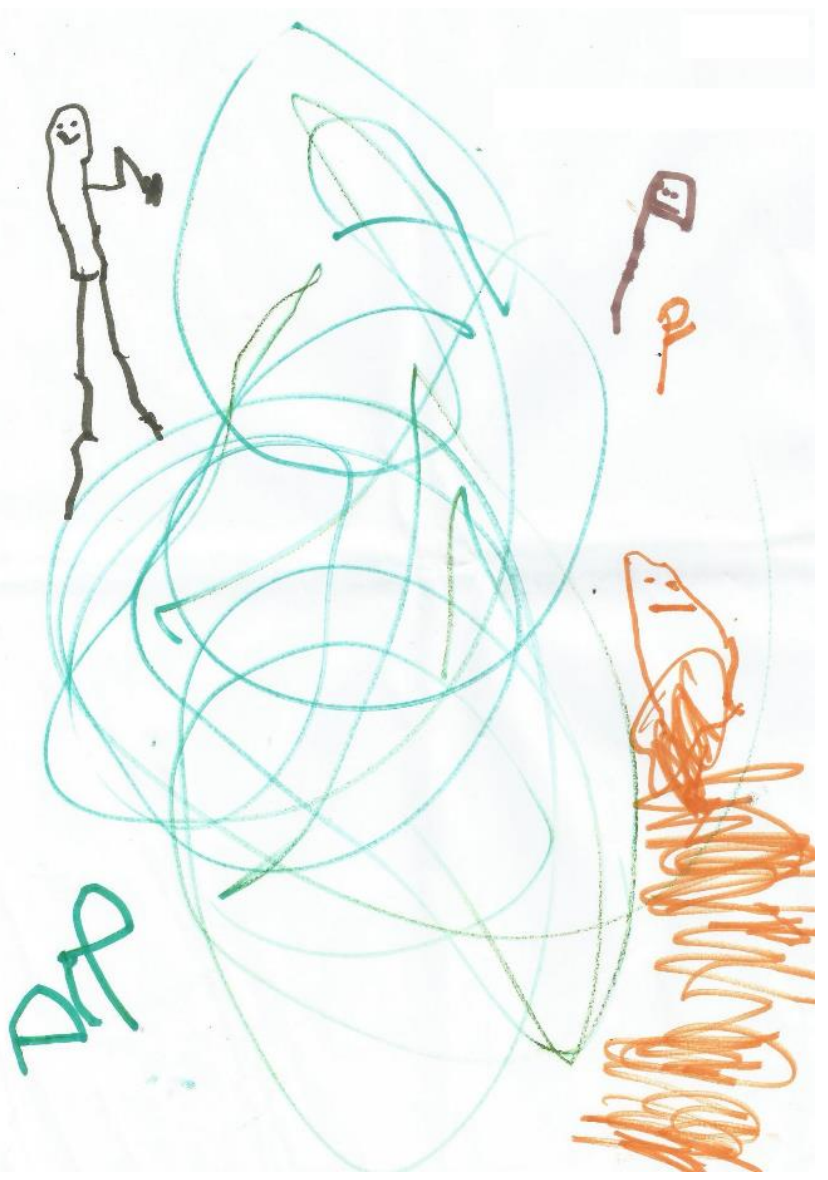

Figura 10 - Conexões... - Fonte: Arquivo pessoal

Se "[...] toda máquina é o corte de fluxo em relação àquela com que está conectada" (DELEUZE, GUATARRI, 2010, p. 55), os desenhos das crianças funcionam para que problematizemos as máquinas desejantes criadas por elas nos fluxos e cortes, na produção de uma produção. Ou seja, no encontro com a produção de "poções mágicas", as crianças criaram outras conexões de uma máquina que produziram fluxos em outra a ela conectada, processando, assim, um corte, uma interrupção dos fluxos.

A tarefa da pintura está definida como a tentativa de tornar visíveis as forças que não são visíveis. O mesmo vale para a música, de esforçar-se por torna sonoras as forças que não o são. É evidente. A força está em relação estreita com a sensação: é preciso que uma força se exerça sobre um corpo, na forma de uma onda, para que haja sensação (DELEUZE, 2007, p. 62). 


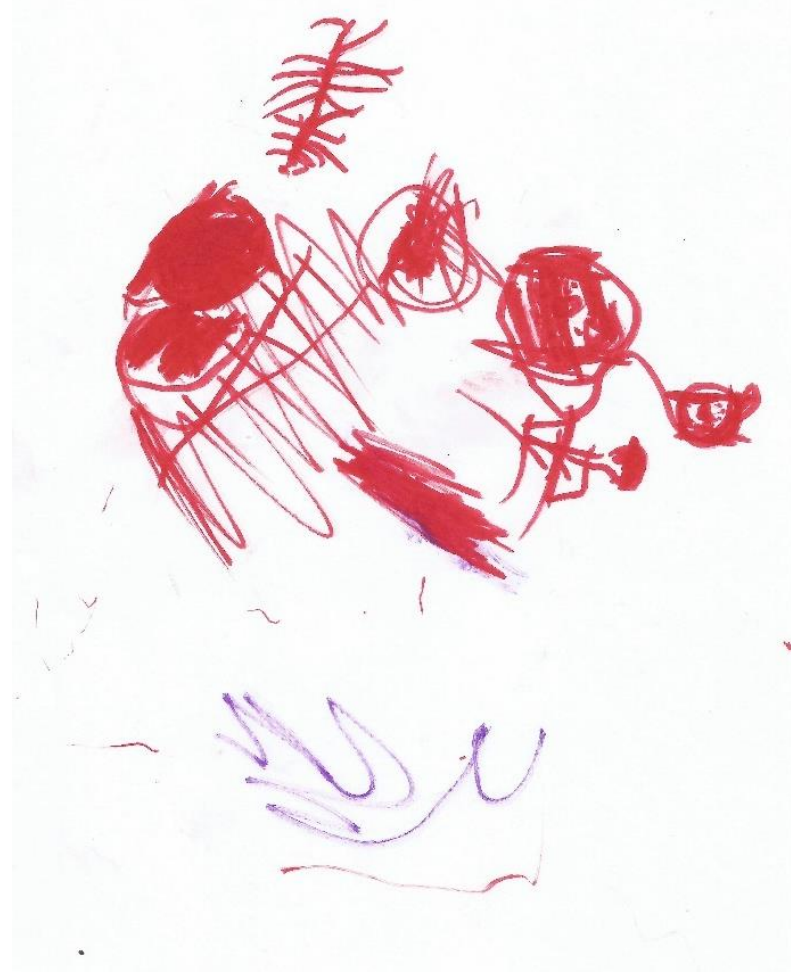

Figura 11 - Desdobramentos, ressonâncias e contágios... - Fonte: Arquivo pessoal

A força deste texto está nas máquinas desejantes das crianças em seus desenhos intensivos e na maneira como podemos pensar as suas produções. Suas criações e fabulações auxiliamnos a problematizar a definição de que máquina desejante "[...] é o seu poder de conexão ao infinito, em todos os sentidos e em todas as direções" (DELEUZE, GUATARRI, 2010, p. 514).

Desse modo, o convite que fazemos com este texto é afetar-se pelos desenhos das crianças. Depois de conhecer o que atravessou esse grupo de crianças de 3 anos, observe, sinta, fabule e invente com os desenhos que compõem este texto, pois essas conexões anunciam a potência das crianças, ao pintarem com as forças do mundo. E quem pode definir a força fabulativa de uma criança?

\section{Referências}

DELEUZE, G. Espinosa e o problema da expressão. São Paulo: Ed 34, 2017.

DELEUZE, G. Lógica da sensação. Rio de Janeiro: Jorge Zahar Editora, 2007.

DELEUZE, G.; GUATTARI, F. O anti-Édipo. São Paulo: Ed 34, 2010.

LAPOUJADE, D. Existências mínimas. São Paulo. Editora n-1, 2017.

MERÇON, J. Aprendizado ético-afetivo: uma leitura spinoziana da educação. Campinas: Alínea, 2009.

SPINOZA, B. Ética. Trad. Tomaz T. Silva. Belo Horizonte: Autêntica, 2007. 